\title{
The performance and the characterization of laser ablation aerosol particle time-of-flight mass spectrometry (LAAP-ToF-MS)
}

\author{
Rachel Gemayel $^{1}$, Stig Hellebust ${ }^{1, a}$, Brice Temime-Roussel ${ }^{1}$, Nathalie Hayeck ${ }^{1, b}$, Johannes T. Van Elteren ${ }^{2}$, \\ Henri Wortham $^{1}$, and Sasho Gligorovski ${ }^{1}$ \\ ${ }^{1}$ Aix Marseille Université, CNRS, LCE UMR 7376, 13331, Marseille, France \\ ${ }^{2}$ National Institute of Chemistry, Slovenia, Laboratory for Analytical Chemistry, Hajdrihova 19, 1000 Ljubljana, Slovenia \\ ${ }^{a}$ now at: Central Statistics Office, Cork, Ireland \\ b now at: Université de Lyon 1, CNRS, UMR 5256, IRCELYON, Institut de Recherches sur la Catalyse et \\ l'Environnement de Lyon, Villeurbanne, 69626, France
}

Correspondence to: Rachel Gemayel (rachel.gemayel@etu.univ-amu.fr)

and Sasho Gligorovski (saso.gligorovski@univ-amu.fr)

Received: 18 November 2015 - Published in Atmos. Meas. Tech. Discuss.: 20 January 2016

Revised: 6 April 2016 - Accepted: 13 April 2016 - Published: 2 May 2016

\begin{abstract}
Hyphenated laser ablation-mass spectrometry instruments have been recognized as useful analytical tools for the detection and chemical characterization of aerosol particles. Here we describe the performances of a laser ablation aerosol particle time-of-flight mass spectrometer (LAAPToF-MS) which was designed for aerodynamic particle sizing using two $405 \mathrm{~nm}$ scattering lasers and characterization of the chemical composition of single aerosol particle via ablation/ionization by a $193 \mathrm{~nm}$ excimer laser and detection in a bipolar time-of-flight mass spectrometer with a mass resolving power of $m / \Delta m>600$.

We describe a laboratory based optimization strategy for the development of an analytical methodology for characterization of atmospheric particles using the LAAP-ToF-MS instrument in combination with a particle generator, a differential mobility analyzer and an optical particle counter. We investigated the influence of particle number concentration, particle size and particle composition on the detection efficiency. The detection efficiency is a product of the scattering efficiency of the laser diodes and the ionization efficiency or hit rate of the excimer laser. The scattering efficiency was found to vary between 0.6 and $1.9 \%$ with an average of $1.1 \%$; the relative standard deviation (RSD) was $17.0 \%$. The hit rate exhibited good repeatability with an average value of $63 \%$ and an RSD of $18 \%$. In addition to laboratory tests,
\end{abstract}

the LAAP-ToF-MS was used to sample ambient air during a period of 6 days at the campus of Aix-Marseille University, situated in the city center of Marseille, France. The optimized LAAP-ToF-MS methodology enables high temporal resolution measurements of the chemical composition of ambient particles, provides new insights into environmental science, and a new investigative tool for atmospheric chemistry and physics, aerosol science and health impact studies.

\section{Introduction}

Atmospheric aerosols, defined as an assembly of solid or liquid particles suspended in a gas (Finlayson-Pitts and Pitts, 2000), have a large impact on human health (Dockery and Pope, 2006) and global climate (Poeschl, 2005). Ambient aerosols typically span a size range from $3 \mathrm{~nm}$ to $10 \mu \mathrm{m}$ in diameter. Between these particles, those with a diameter larger than $5 \mu \mathrm{m}$ are rapidly removed by gravitational settling while aerosols with a diameter in the nanometer range, depending on the chemical composition and local meteorology, may drift in the atmosphere for a prolonged period of time. Most of the elements that are vaporized during various human activities (e.g., coal combustion) tend to condense and form fine particles with a high surface-to-volume ratio which can 
be transported over long distances (Canagaratna et al., 2007). In addition, the smaller particles exhibit more adverse health effects compared to the larger particles since they are more likely to penetrate the human lung and even enter the blood stream (Dockery and Pope, 2006). A recent study (Lelieveld et al., 2015) has shown that outdoor air pollution leads to 3.3 million premature deaths per year worldwide, predominantly in Asia, mostly due to $\mathrm{PM}_{2.5}$ (particulate matter). This figure could double by 2050 if emissions continue to rise at the current rate.

A detailed understanding of the particle sizes and the chemical composition of atmospheric particles is of paramount importance to understand their impact on health and climate. Hence, there is a need for the development of appropriate analytical methods for on-line, time-resolved measurements of atmospheric particles. In the last decade several hyphenated laser ablation - mass spectrometry instruments have been developed (see for instance Gaie-Levrel et al. (2012) with the aim of chemically characterizing aerosol particles. Murphy (2007) has reviewed the development and implementation of single particle laser mass spectrometers. These instruments appear promising for aerodynamic sizing of particles and characterization of their chemical composition. The advantage of using laser ionization compared to methods based on thermal desorption, such as that applied in the aerosol mass spectrometer (AMS), is the ability to analyze both non-refractory (e.g., organics, ammonium nitrate) and refractory (e.g., mineral dust, soot) components of individual atmospheric aerosol particles (Pratt and Prather, 2011). However, a deeper investigation is required in order to promote the laser ionization technique as a suitable experimental device for the elemental quantification of individual aerosol particles. The recently launched Laser Ablation Aerosol Particle Time-of-Flight Mass Spectrometer (LAAPToF-MS), based on laser desorption and ionization, provides information on the aerodynamic diameter and chemical composition of individual aerosol particles. LAAP-ToF-MS is intended for on-line and continuous measurement of atmospheric particles with an analysis time in the order of milliseconds per particle.

Here we present a laboratory-based study of the LAAPToF-MS instrument performance and a novel approach to developing an analytical methodology for continuous monitoring of particle size distribution and their composition using this instrument. It will allow both qualitative information on single particles and quantitative information about ambient particle ensembles to be obtained simultaneously.

\section{Experimental}

\subsection{Description of the LAAP-ToF-MS instrument}

The LAAP-ToF-MS instrument (AeroMegt, $\mathrm{GmbH}$ ) features an aerodynamic particle lens inlet, a particle-sizing region using two scattering lasers, a bipolar time-of-flight mass spectrometer and an excimer laser as ablation/ionization laser. The particle inlet is comprised of an aerodynamic lens with a transmission for particles with an aerodynamic diameter between 80 and $600 \mathrm{~nm}$. The working principle of the LAAP-ToF-MS is shown in Fig. 1a.

The aerosol particles leave the differential pumping stages (inlet) and enter into the detection region where they pass through the region irradiated with light $(\lambda=405 \mathrm{~nm})$, emitted by two continuous wave (cw) lasers (scattering lasers) with a power range between 100 and $450 \mathrm{~mW}$, facilitating particle sizing by light scattering. The flight path between the two laser beams has a length of $11.5 \mathrm{~cm}$. The time between the two scattering events, i.e. the particle's time of flight, is recorded and used to calculate the aerodynamic particle size. In addition, the second scattering event triggers the excimer laser that fires and ablates the drifting particle in its path. The ionization laser is a $193 \mathrm{~nm} \mathrm{ArF}^{*}$ excimer laser (GAM Laser Inc.) with a maximum energy of $10 \mathrm{~mJ}$ per pulse (pulse duration $\sim 10 \mathrm{~ns}$ ) enabling ablation of single particles every $4 \mu \mathrm{s}$. The LAAP-ToF-MS is operational in three modes of fast triggering. (i) The first mode provides information about the particle size and chemical composition of individual aerosol particles; in this mode the excimer laser is triggered by two consecutive light scattering events in both diodes. (ii) In the second mode the excimer laser is triggered by the second scattering laser only, allowing the calculation of high particle hit rates, without providing size information on the particles. (iii) In the third mode the excimer laser is fired without a trigger pulse at constant frequency in the range between 1 and $100 \mathrm{~Hz}$ and particles will be ablated arbitrarily if they happen to be in the path of the laser beam. In this study, only the performance of the first mode will be described. In this mode it is possible to study the chemical composition as a function of the particle size (Buzea et al., 2007).

After ablation, the charged ions are extracted into a bipolar time-of-flight mass spectrometer (Tofwerk, BTOF) with a resolving power of $m / \Delta m \geq 600 \mathrm{FWHM}$ (Full Width at Half Maximum) for both ion polarities. The ions are extracted into their corresponding flight region (positive or negative ions) and detected by microchannel plate detectors (MCPs). Positive and negative ions are detected independently; both mass spectra (positive and negative), as well as the related scattering signals, are recorded together and can be further analyzed.

\subsection{Experimental setup}

\subsubsection{Laboratory experiments}

Two types of particles were used for laboratory experiments, spherical particles of Polystyrene Latex beads (PSL, Duke Scientific Corp) with a factor shape equal to 1 and a density of $1.05 \mathrm{~g} \mathrm{~mL}^{-1}$, and ammonium nitrate particles (ACROS organics) with a factor shape equal to 0.8 and a density of $1.7 \mathrm{~g} \mathrm{~mL}^{-1}$. These particles were generated by an atomizer 

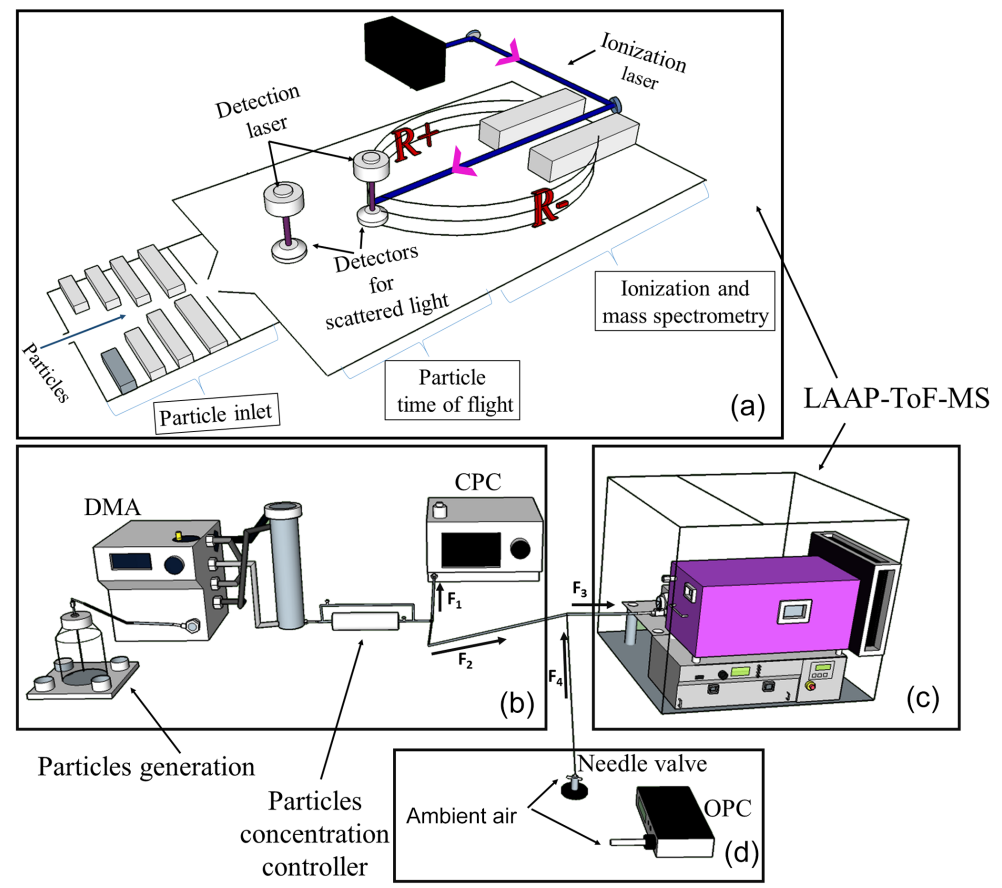

Figure 1. (a) Schematic diagram of the working principle of LAAP-ToF-MS, (b-c) Experimental configuration aimed to investigate the influence of particle density, size effect and detection efficiency, and (c-d) Experimental configuration for aerosol particle measurement.

(model 3076, TSI, US). A diffusion dryer (model 3306, TSI, US) was used to decrease the humidity so it does not affect the hit rate and the particle size. The number concentration is regulated by a concentration controller. To control the number concentration in the sample flow, the particle flow is split into two, one flow path passing through the particle filter while the second one goes through a normal tube. The two flows are then merged at the outlet of the concentration controller. By increasing the fraction of the flow passing through the filter, the particle number concentration decreases.

The experimental configurations were designed to investigate the instrument's performance in the first mode of operation, with particle sizing. The first outline (Fig. 1b-c) was employed to study the repeatability, the size calibration and the effect of the particle size and the particle number concentration on the hit rate of the excimer laser (HR) and the scattering efficiency of the scattering lasers $(E)$. The differential mobility analyzer (DMA 3081, TSI, US, impactor size $0.071 \mathrm{~cm}$, sample flow $=0.3 \mathrm{~L} \mathrm{~min}^{-1}$ (liter per minute), sheath flow $=3.0 \mathrm{~L} \mathrm{~min}^{-1}$ ) was placed downstream of the particle generation assembly and was set to select particles in the required size range between 15 and $773 \mathrm{~nm}$. The sized particle stream leaving the DMA was split between a condensation particle counter (CPC 3776, TSI) $\left(F_{1}=0.3 \mathrm{~L} \mathrm{~min}^{-1}\right)$ and the LAAP-ToF-MS $\left(F_{2}=F_{3}=0.08 \mathrm{~L} \mathrm{~min}^{-1}\right)$, to obtain independent measurements of the number of particles per second and the particles' number in the DMA-selected size range, respectively, allowing calculation of the scattering efficiency and the detection rate.

\subsubsection{Ambient measurements}

The second configuration (Fig. 1d-c) was used for the measurement of atmospheric particles. This second configuration was designed to assess the potential effect of chemical composition on the hit rate and the scattering efficiency of real particles and to assess the effect of the number concentration. The chemical composition, particle size and the number evolution of the ambient particles were measured continuously by the LAAP-ToF-MS and an optical particle counter (OPC 1.109, Grimm, Germany).

\section{Results and discussion}

\subsection{Detection efficiency}

The first step in the analysis of the processed raw data is to evaluate the detection efficiency and to test the repeatability of the performed analysis. To this end we need to introduce three different concepts of instrumental efficiency. The detection efficiency $\left(D_{\mathrm{E}}\right)$ is defined as a product of the scattering efficiency of the laser diodes $(E)$ and the ionization efficiency of the excimer laser, also known as hit rate (HR):

$D_{\mathrm{E}}(\%)=E \times \mathrm{HR}$.

The scattering efficiency of the laser diodes is defined as the ratio between the frequency of the detected particles by LAAP-ToF-MS and the number of particles detected by the 
CPC per unit of time:

$E(\%)=\frac{N \times 100}{c \times U \times t}$,

where $N$ is the number of particles detected by the laser diodes of the LAAP-ToF-MS, $c$ is the number concentration $\left[\mathrm{cm}^{-3}\right], U$ is the aerosol sampling flow rate $\left[80 \mathrm{~mL} \mathrm{~min}^{-1}\right]$ and $t$ is the time [minutes]. The hit rate represents the ratio between the number of ablated/ionized particles and the number of particles detected by the laser diodes:

$\operatorname{HR}(\%)=\frac{N_{i} \times 100}{N}$,

where $N_{i}$ is the number of ablated particles by the excimer laser, which are, in turn, measured by ToF-MS yielding the associated mass spectra. The hit rate depends on the threshold setting discriminating between the useful spectra and total spectra. The intensities of real spectra depend on how successful the laser ablation is. Laser ablation is a process that is hard to replicate because the particles are randomly ablated. Thus, each particle ablation event is different: (1) particles can be completely missed by the laser pulse, (2) there can be partially ablated particles, and there can be (3) completely ablated particles. The threshold is considered as a better discriminant than other measures, such as spectral variance around the baseline, because it allows low-intensity spectra to be included in the useful category, while excluding spectra without distinct peaks, but which may have noisy baselines. Inspection of excluded spectra is necessary for assessing the correct value of the discriminant, i.e. the threshold.

\subsection{Repeatability}

\section{Laboratory experiments}

The repeatability of the LAAP-ToF-MS instrument was tested by continuous analysis of polystyrene latex (PSL) particles with a diameter of $450 \mathrm{~nm}$ and a number concentration of $39 \pm 5$ particles $\mathrm{cm}^{-3}$. The period of repeatability tests is limited by the use of silica gel for particles drying which is efficient for $53 \mathrm{~h}$ maximum. The repeatability test for both the scattering efficiency and the hit rate, during the total time period of $53 \mathrm{~h}$, is shown in Fig. 2.

Every point in this figure corresponds to an average of detected particles during a period of $3 \mathrm{~min}$, which is a minimum time interval necessary to attain sufficient number of detected particles. The scattering efficiency varies between 0.6 and $1.9 \%$ with an average of $1.1 \%$. The relative standard deviation (RSD) is $17 \%$ over the entire period of $53 \mathrm{~h}$ of analysis. The hit rate exhibits good repeatability with an average value of $63 \%$ and the RSD is $18 \%$. The scattering efficiency may decrease due to larger particles passing through the critical orifice leading to a lower flow rate in the inlet. The argon fluoride gas lifetime is another important parameter which influences the hit rate. To test this parameter we generated
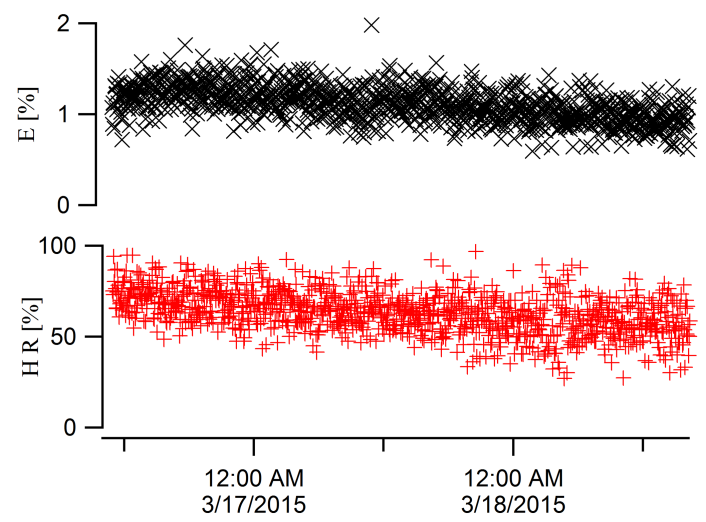

Figure 2. Repeatability of the scattering efficiency $(E)$ and the hit rate $(\mathrm{HR})$, during a time period of $53 \mathrm{~h}$.

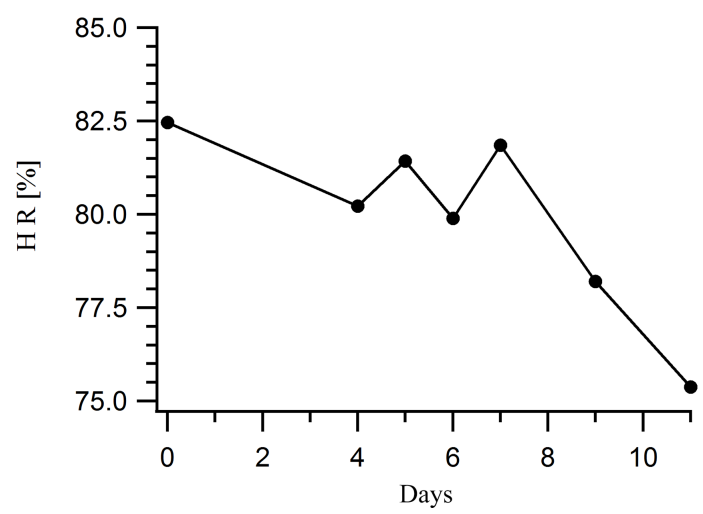

Figure 3. The influence of the ArF gas life time on the evolution of the laser hit rate (HR) over the time.

PSL particles with a diameter of $450 \mathrm{~nm}$ seven times for few minutes each and then measured the hit rate. The first measurement was made immediately after refilling the excimer laser and the time difference between the first measurement and the last one was 12 days. Figure 3 shows the variation of the hit rate with time. During the first week the hit rate is considered constant, and from the eighth day it begins to decrease. Four weeks after refilling the excimer laser the hit rate has dropped down to zero upon daily use of the laser. According to the Laser Gam Ex5 specifications, laser energy drops to $50 \%$ after a shelf life of 12 days or after 12 million pulses of ArF excimer laser. It seems that the shelf life is the limiting factor when using the laser in association with single particle mass spectrometer, at least in the diode trigger modes. Therefore, the data shown in Fig. 3 correspond only to the first 12 days.

The alignments of the scattering laser, aerodynamics lenses and the ionization laser are done manually. Therefore, the average of scattering efficiency and the hit rate are not the same as above for the experiments discussed in the rest of this article. However, the values of repeatability are expressed as relative standard deviation, which is not based on 


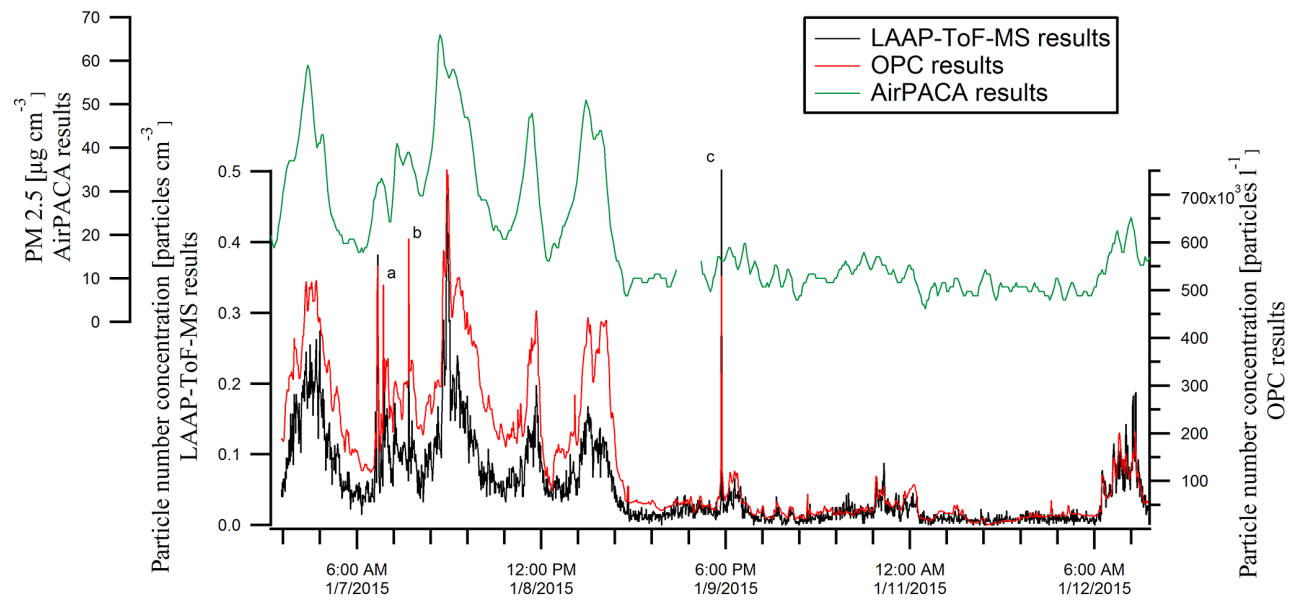

Figure 4. The total particle number concentration detected by LAAP-ToF-MS and OPC as a function of time; indicated are peaks corresponding to smoking events ( $\mathbf{a}$ and $\mathbf{b}$ ) and to generation of $\mathrm{TiO}_{2}(\mathbf{c})$. The total $\mathrm{PM}_{2.5}$ results according to Air PACA are depicted in green.

the alignment. Therefore, for a good repeatability of the scattering efficiency during a field campaign it is important to filter out large particles to maintain a constant flow in the inlet for as long as possible, while for a good repeatability of the hit rate it is strongly recommended that the excimer laser is refilled once a week.

\subsection{Ambient measurements}

Ambient aerosol measurements were performed on the campus of Aix-Marseille University, situated in the city center of Marseille, France. The ambient air was simultaneously sampled by LAAP-ToF-MS and OPC for a period of 6 days. A total of 62813 bipolar mass spectra of single particles with different sizes were recorded, among which 36433 spectra were useful.This corresponded to a hit rate of $58 \%$. The number of particles detected every $5 \mathrm{~min}$ by OPC, in the range between $265 \mathrm{~nm}$ and $3 \mu \mathrm{m}$ (aerodynamic diameter), is shown in Fig. 4. The total number of particles in the range between $200 \mathrm{~nm}$ and $3 \mu \mathrm{m}$ (aerodynamic diameter), detected every $5 \mathrm{~min}$ by LAAP-ToF-MS is also depicted.

As shown in Fig. 4, there are three peak events detected during this monitoring campaign. Two of these particle number concentration spikes (a and b), with maxima of 510.9 and 607.5 particles $\mathrm{cm}^{-3}$, were detected on 7 January 2015 at 10:17 a.m. and 02:27 p.m., respectively, correspond to smoking events near the building. The third peak (c), detected on 9 January 2015 is related to the generation of $\mathrm{TiO}_{2}$ particles that we intentionally introduced to the ambient air. Although, these phenomena only lasted a few minutes they were detected by LAAP-ToF-MS. As can be observed from Fig. 4 there is a strong agreement between the three peaks detected by OPC and LAAP-ToF-MS. Figure 4 also shows good agreement between the particle number concentrations detected by LAAP-ToF-MS and the results obtained by the air monitoring station (Air PACA) which is located at $1.6 \mathrm{~km}$ distance from our sampling site. The results of Air PACA shown in Fig. 4 correspond to the particle mass concentrations of $\mathrm{PM}_{2.5}$. The absence of the three peaks detected by LAAP-ToF-MS is logical since these peaks were caused by events happening on the sampling site, as described above.

The LAAP-ToF-MS measurements permit the identification and the monitoring of several types of ions. Figure 10 shows the standard deviation of all superimposed positive and negative ions mass spectra.

The negative ion mass spectra contain peaks associated with elemental carbon $\left({ }^{24} \mathrm{C}_{2}^{-}\right)$, nitrate $\left({ }^{46} \mathrm{NO}_{2}^{-}\right)$and sulfate $\left({ }^{97} \mathrm{HSO}_{4}^{-}\right)$. The presence of cyanide $\left({ }^{26} \mathrm{CN}^{-}\right),\left({ }^{17} \mathrm{OH}^{-}\right)$, $\left({ }^{35} \mathrm{Cl}^{-}\right)$can also be observed in Fig. 5. In the positive ion spectra, the identified ion peaks are associated with elemental carbon $\left({ }^{12} \mathrm{C}_{1}^{+},{ }^{24} \mathrm{C}_{2}^{+},{ }^{36} \mathrm{C}_{3}^{+}\right)$and nitrate $\left({ }^{30} \mathrm{NO}^{+}\right)$. Also potassium $\left({ }^{39} \mathrm{~K}^{+}\right)$and to a lesser extent sodium $\left({ }^{23} \mathrm{Na}^{+}\right)$and silicon $\left({ }^{28} \mathrm{Si}^{+}\right)$are present. The two specific ions related to $\mathrm{TiO}_{2}\left({ }^{48} \mathrm{Ti}^{+}\right.$and $\left.{ }^{64} \mathrm{TiO}^{+}\right)$were also observed. Other metal ions such as lead, cerium and tin were also detected. The source apportionment of these elements is outside the scope of this article.

\subsection{Parameters influencing the detection efficiency}

The detection efficiency of the particles can be influenced by the particle number concentration in the sample flow, the size of the particles and the chemical composition which can vary during the analysis. For this purpose, five different number concentrations of ferric sulfate particles ranging between 50 and 1200 particles $\mathrm{cm}^{-3}$ were analyzed to evaluate the number concentration effect. On the other hand five different sizes of PSL particles $(350,450,500,600,700 \mathrm{~nm})$ were analyzed at the same particle number concentration, 20 particles $\mathrm{cm}^{-3}$, to assess the particle size effect. Several repeat particle analyses were performed for each particle size and particle number concentration. 

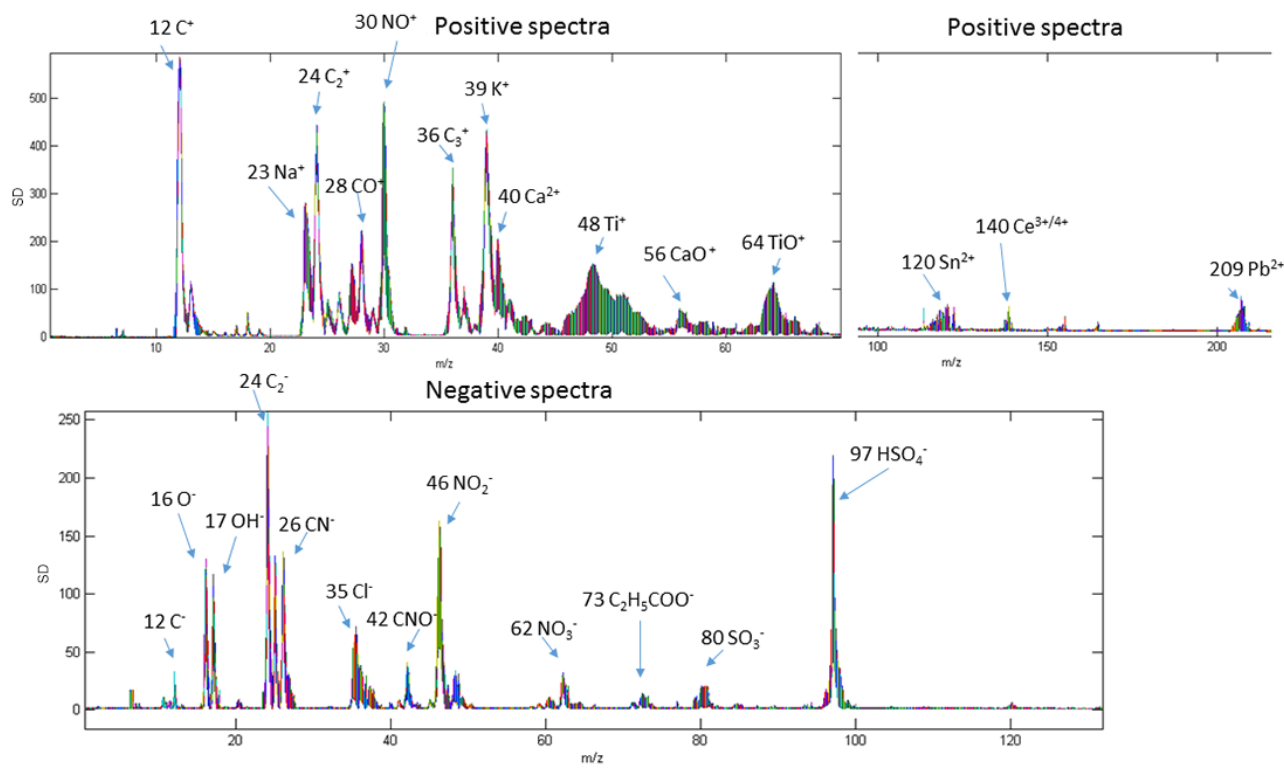

Figure 5. The standard deviation of all positive and negative ion mass spectra.

\subsubsection{Size effect}

\section{Laboratory experiments}

To test the influence of particle size on the efficiency of the scattering lasers and the hit rate of the excimer laser, five different sizes of PSL particles (350, 450, 500, 600, $700 \mathrm{~nm}$ ) were analyzed at constant particle concentration of 20 particles $\mathrm{cm}^{-3}$. For this particle concentration, particles smaller than $350 \mathrm{~nm}$ are undetectable. The RSD for each particle size, obtained from several replicate analyses, was compared to the coefficient of variation corresponding to different particle sizes. The particle size influences both the laser scattering efficiency and the hit rate, and therefore the detection efficiency of LAAP-ToF-MS (Fig. 6), as well.

Figure 6 shows that the hit rate decreases with the particle diameter, from 93 to $83 \%$ when the diameter decreases from 600 to $350 \mathrm{~nm}$. This behavior can be explained by the fact that smaller particles drift with higher velocity. Thus, the ions generated by the ionization laser have a higher kinetic energy resulting in aberrations (Murphy, 2007). A maximum efficiency of $2.5 \%$ for the laser scattering diodes was observed for particles with a diameter of $450 \mathrm{~nm}$ and a lower efficiency for smaller particles. When the size of the individual particles becomes equivalent to or greater than the wavelength of the laser $(\lambda=403 \mathrm{~nm})$, the scattering becomes a complex function with maxima and minima with respect to the incident angle according to Mie theory (Finlayson-Pitts and Pitts, 2000). As the diameter of the particle drops below the wavelength of the scattering laser the scatter intensity decreases rapidly, inversely proportional to the sixth power of the particle diameter $\left(1 / d^{6}\right)$.
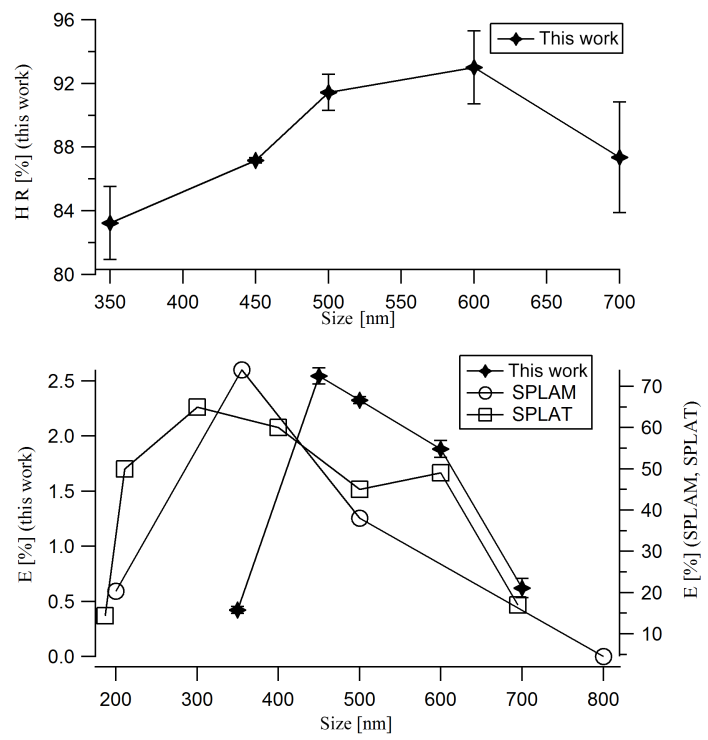

Figure 6. The scattering efficiency and the hit rate as a function of the size of various PSL particles $(350,450,500,600$, and $700 \mathrm{~nm})$ at a particle number concentration of $20 \mathrm{~cm}^{-3}$. The SPLAT and SPLAM scattering detection efficiency results are given for comparison purpose.

The scattering efficiency decreases again for particles with a $d_{\mathrm{va}}$ diameter greater than $600 \mathrm{~nm}$ as only the particles in the range between 80 and $600 \mathrm{~nm}$ are transmitted at $100 \%$ by the aerodynamic lenses.

A comparison between the scattering efficiencies of LAAP-ToF-MS, the single particle laser ablation mass spectrometer (SPLAM) (Gaie-Levrel et al., 2012) and the sin- 
gle particle laser ablation time-of-flight mass spectrometer (SPLAT) (Zelenyuk and Imre, 2005) has been undertaken (Fig. 6). The scattering efficiency of SPLAT decreases slightly for particles higher than $300 \mathrm{~nm}$ compared to SPLAM or LAAP-ToF-MS. The scattering efficiency shows the same behavior for LAAP-ToF-MS and SPLAM which can be ascribed to the same operating wavelengths of the scattering lasers $(\lambda=405 \mathrm{~nm}$ for SPLAM). However, the scattering efficiency of SPLAM is much higher than that of LAAP-ToF-MS, which can be explained by the much smaller distance $\left(d_{\mathrm{d}}\right)$ between the two scattering lasers within SPLAM, i.e. 4.1 vs. $11.5 \mathrm{~cm}$ for LAAP-ToF-MS. Another advantage of SPLAM compared to the LAAP-ToF-MS is the higher value of $C_{\max }$ which is ascribed to the small $d_{\mathrm{d}}$. The distance between the two scattering lasers influences the $C_{\max }$ for a particle size of $350 \mathrm{~nm}$ and a velocity of $103 \mathrm{~m} \mathrm{~s}^{-1}$, the $C_{\max }$ of LAAP-ToF-MS is 618 particles $\mathrm{cm}^{-3}$ whereas the $C_{\max }$ of SPLAM for the same particle size and a velocity of $100 \mathrm{~m} \mathrm{~s}^{-1}$ is $1.7 \times 10^{3}$ particles $\mathrm{cm}^{-3}$. The ratio between the $d_{\mathrm{d}}$ of SPLAM and LAAP-ToF-MS is 2.87 and is similar to the ratio between the $C_{\max }$ of SPLAM and LAAP-ToF-MS (2.75), which explains that divergence of the particle beam increases with $d_{\mathrm{d}}$ and is more pronounced for smaller particle sizes. In comparison to SPLAM, which uses ionization laser at $\lambda=248 \mathrm{~nm}$, the ablation of the particles by LAAP-ToF-MS occurs at $193 \mathrm{~nm}$ which means that even metals can be ionized. A big advantage of LAAP-ToF-MS compared to SPLAM or SPLAT is the much higher hit rate. For LAAP-ToF-MS the effective hit rate is $90 \%$ for PSL particles and $58 \%$ for atmospheric particles, while the hit rate of SPLAT is only $8 \%$ for atmospheric particles. Also, LAAPToF-MS is an easily transportable tool for fast field deployment.

Finally, a comparison was carried out with another similar instrument named Aerosol Time of Flight Mass Spectrometer (ATOFMS) (Gard et al., 1997). This instrument operates at $266 \mathrm{~nm}$ unlike the LAAP-TOF-MS $(\lambda=193 \mathrm{~nm})$. The lower wavelength of the ionization laser enables the analysis of trace metals. There are few papers in the literature referring to the development of ATOFMS associated with detection of different size of particles (Allen et al., 2000; Su et al., 2004; Zauscher et al., 2011). For example, the detection efficiency of ATOFMS is highest for the ambient particles with diameter of $1.8 \mu \mathrm{m}$ and decreases for about 3 orders of magnitude for the lowest size that is $320 \mathrm{~nm}$ (Allen et al., 2000). Su et al. (2004) reported that ATOFMS is able to detect small size particles ranging between 70 and $300 \mathrm{~nm}$ with detection efficiency varying between 0.3 and $44.5 \%$.

In any case, it should be noted that size has an impact on the detection efficiency as we mentioned above.

\section{Ambient measurements}

We assessed the size effect of ambient aerosols on the hit rate and on the scattering efficiency. For each size in the range between $10 \mathrm{~nm}$ and $2.5 \mu \mathrm{m}$ (aerodynamic diameter) we are showing (Fig. 7) the total number of particles detected by the LAAP-ToF-MS during the measurements by the scattering lasers and also the total number of ionized particles during the measurements.

The optimum particle size for detection is in the range between 400 and $600 \mathrm{~nm}$ (aerodynamic diameter), in the same range as the wavelength of ionization $(\lambda=403 \mathrm{~nm})$. The Fig. $7 \mathrm{~b}$ shows the time evolution of the particle concentration. It can be seen that in the ambient air the maximum particle number concentration corresponds to the lowest size range $\left(d_{\mathrm{va}}<300 \mathrm{~nm}\right)$. The comparison between the results of the Fig. 7a and the results of the Fig. 7b confirm the conclusions from laboratory tests that the scattering efficiency is affected by the size of particles and its maximum is influenced according to the Mie theory.

In addition, Fig. 7a shows that the hit rate for ambient aerosol as function of the size range is different from the laboratory results. This difference can be ascribed to the effect of chemical composition which is detailed in Sect. 3.4.3.

Figure $7 \mathrm{c}$ shows the evolution of the number of spectra in each size range every $5 \mathrm{~min}$ during the measurements. Since the scattering efficiency and the hit rate are affected by the particle size, so is the detection efficiency (Fig. 7c). Most of the usable spectra are in the range between 400 and $500 \mathrm{~nm}$. The effect of particle size is overcome by clustering the spectra obtained for each size range and multiplying the number of ionized particle by the detection efficiency $(D \%=E \times \mathrm{HR})$ corresponding to each size range.

\subsubsection{Effect of the distance between the two scattering laser}

\section{Laboratory experiments}

We investigated the transmission efficiency between the first and the second scattering laser, considering that the two laser diodes have the same characteristics. However, the first scattering laser exhibits a much higher efficiency $\left(E_{\mathrm{d} 1}\right)$ than the second scattering laser $\left(E_{\mathrm{d} 2}\right)$. This observation is a consequence of the divergence of the particles between the two laser diodes. In order to understand the magnitude of the particle divergence we researched into the relationship between the ratio of scattering efficiencies $E_{\mathrm{d} 2} / E_{\mathrm{d} 1}(\%)$ and the particle size. Figure 8 displays a parabolic dependency of the ratio of the scattering efficiencies with the size of the PSL particles generated, indicating that velocity indeed plays an important role.

Smaller particles with a diameter of $350 \mathrm{~nm}$ exhibit higher velocities and diverge much more than bigger particles with a size of $600 \mathrm{~nm}$. This curve also explains the lower scattering efficiency of particles with a diameter of $350 \mathrm{~nm}$ displayed in Fig. 8. 


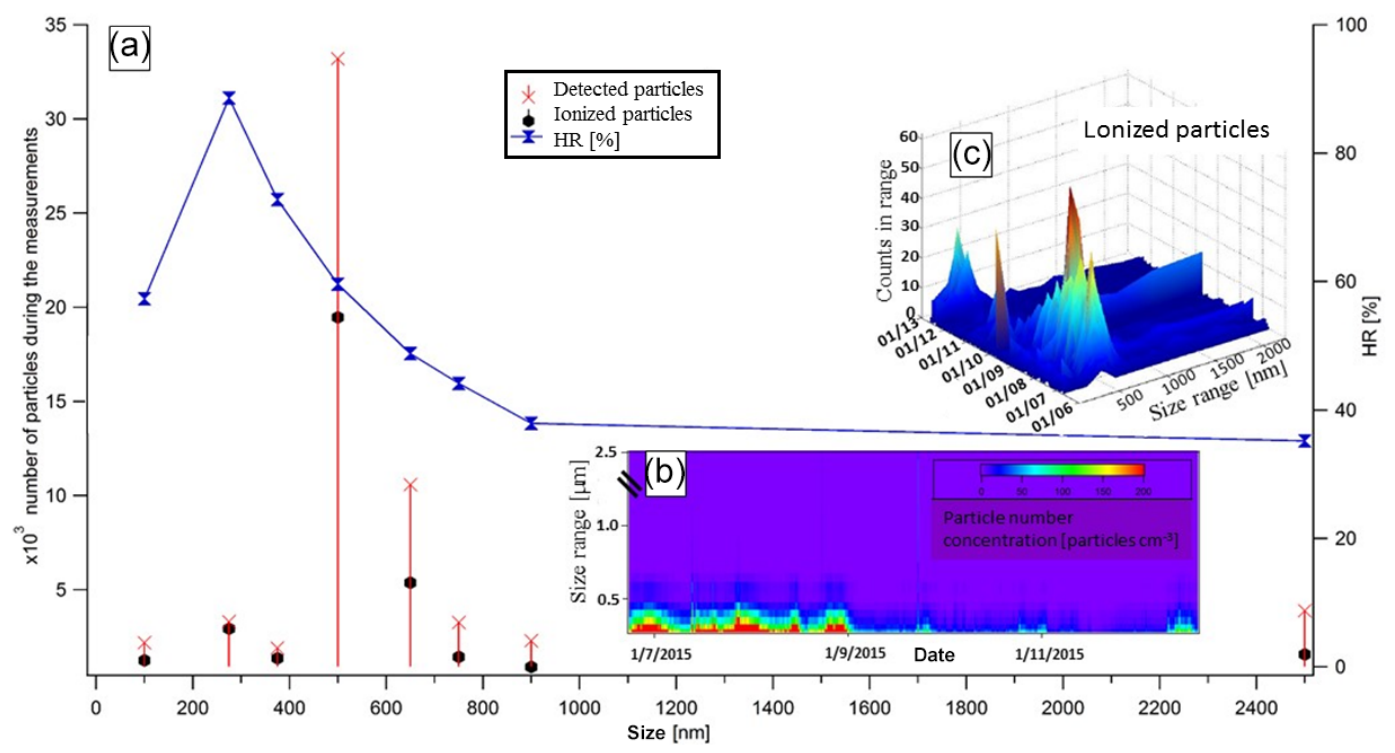

Figure 7. (a) Total number of particles detected and ionized during the ambient measurements in different size range and the hit rate corresponding to each size range (aerodynamic diameter). (b) The evolution of the particle number concentration of the ambient aerosol detected by the OPC during the measurements for different size range depicted between 275 and 2500 nm (aerodynamic diameter). (c) The evolution of the number of particles ionized during the ambient measurements in different size range depicted between 10 and $2500 \mathrm{~nm}$.

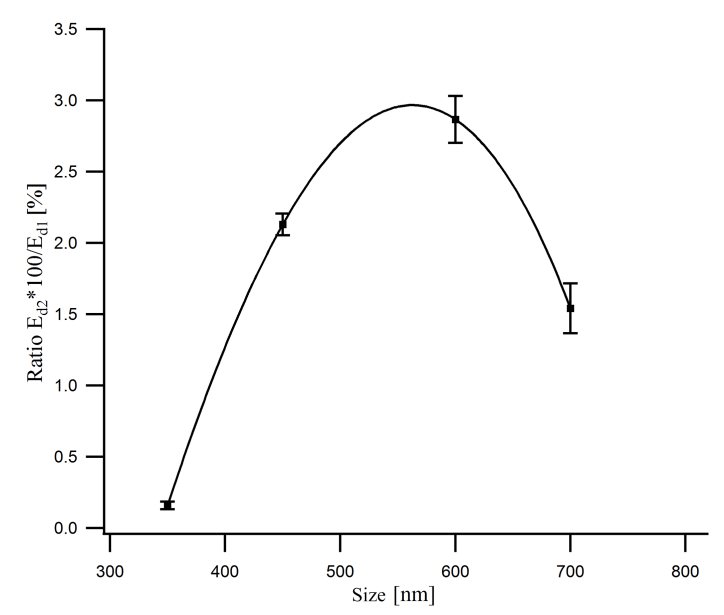

Figure 8. The ratio $E_{\mathrm{d} 2} / E_{\mathrm{d} 1}(\%)$ as a function of the PSL particle size.

In this study there are no information about the values of detection limit in number concentration for each particle size, because this limit is different for each type of particle.

Liu et al. (1995) have demonstrated that the morphology of the particles is a very important parameter that influences the divergence of particles during their drift between the two scattering lasers. In fact, the divergence of the particles increases for non-spherical particles implying a reduction of the scattering efficiency of the laser diodes.

\subsubsection{Chemical composition}

\section{Laboratory experiments}

The ionization efficiency of the excimer laser depends on the chemical composition of the particles (Pratt and Prather, 2011). Experiments were carried out with two types of particles containing ammonium nitrate and ammonium sulfate in order to assess the effect of chemical composition on LAAP-ToF-MS performance. Although, both particles have the same density $\left(1.74 \pm 0.03 \mathrm{~g} \mathrm{~cm}^{-3}\right)$ and the same shape factor $(0.8)$, the hit rate is completely different. Because sulfate resists ionization (Kane and Johnston, 2001), the hit rate decreases from $60 \%$ for the ammonium nitrate particles to $21 \%$ for the ammonium sulfate particles. The hit rate also strongly depends on the alignment of the ionization laser and on the delay time. A change in the chemical particle composition induces a change in the refractive index. Yoo et al. (1996) evaluated the influence of the refractive index on the scattering efficiency of laser diodes. The higher the refractive index, the smaller the particles that can be measured. Moffet and Prather (2005) developed a method to calibrate the light scattering signal collected from individual particles using the Mie theory to calculate the partial scattering crosssection as a function of the particle diameter. The particle density was used to fit the partial scattering cross-section to the Mie theory (Moffet and Prather, 2005). 

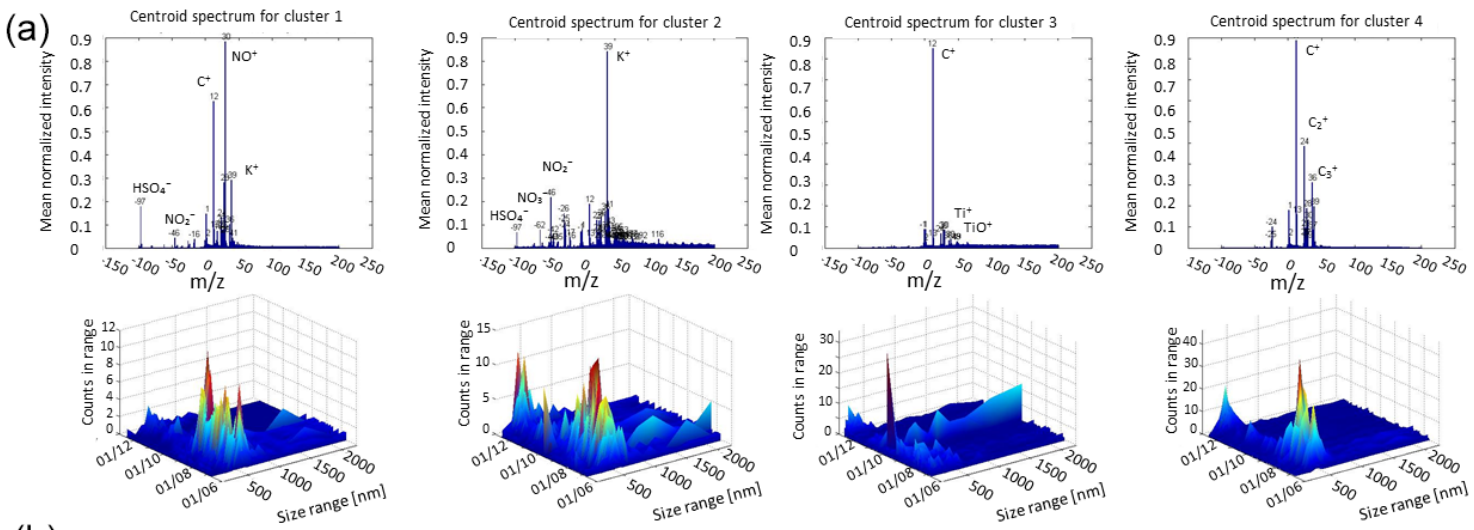

(b)

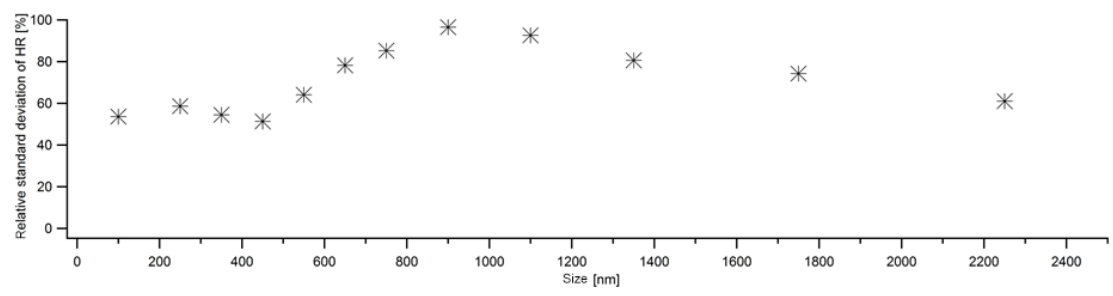

Figure 9. (a) Different clusters of particles and their evolution during the measurements in different size range between 10 and $2500 \mathrm{~nm}$. (b) The standard deviation of the total hit rate calculated every 5 min during the measurements for each size range.

\section{Ambient measurements}

The complete set of spectra can be clustered using the software MATLAB version 2013b into different chemical classes of particles.

Figure 9a illustrates four of these clusters and their repartition every $5 \mathrm{~min}$ in different size range. These clusters were chosen as example to show different kind of inorganics particles, and one cluster with major carbonaceous ions. The inorganic particles are those containing sulfate and nitrate that are considered as secondary particles and particles containing $\mathrm{TiO}_{2}$ that are rather considered as primary particle (Delmas et al., 2005). It can be observed that nitrosium ion $\mathrm{NO}^{+}$ $(m / z=30)$ is abundant in the first cluster and potassium ion $\mathrm{K}^{+}(m / z=39)$ is abundant in the second cluster. The third cluster represents particles with high signals of carbon, and in the fourth cluster characteristic peak of carbon $\mathrm{C}^{+}(\mathrm{m} / \mathrm{z}=$ $12), \mathrm{C}_{2}^{+}(m / z=24), \mathrm{C}_{3}^{+}(m / z=36)$ dominate.

Every cluster has its own repartition, which is defined as a number of particles detected every $5 \mathrm{~min}$ in different size range. Thus, the chemical composition of the particles detected during the measurements is not constant. To show the effect of chemical composition on the hit rate we calculated the hit rate of particles with different size range every $5 \mathrm{~min}$ during the entire time of the measurements. Then we calculated the RSD of the hit rate for each size range. The RSD varies between $51 \%$ for the aerodynamic size range between 400 and $500 \mathrm{~nm}$ to $96 \%$ for aerodynamic size range between 800 and $1000 \mathrm{~nm}$ (Fig. 9b). Comparing the RSD of ambient particles to the RSD calculated of spherical PSL particles during the laboratory tests (Sect. 3.2, repeatability $18 \%$ ), it can be concluded that chemical composition of particles affects the hit rate.

The effect of chemical composition on the hit rate was assessed for particles ranging between 400 and $500 \mathrm{~nm}$ (aerodynamic diameter). Figure 10a shows the evolution of the scattering efficiency and the hit rate for the detected particles between 400 and $500 \mathrm{~nm}$ (aerodynamic diameter).

It can be seen that the hit rate and the scattering efficiency are not constant all the time. As was already seen for a single type of particles the instrument exhibits good repeatability. Therefore the variation in HR (\%) and $E(\%)$ is mainly the consequence of the variation of the chemical composition. In Fig. 10a and $\mathrm{c}$ the variation of the number of three types of particles is represented. The first type (Fig. 10b) represents the particles having an aerodynamic size between 400 and $500 \mathrm{~nm}$ and containing sulfate (cluster 1 and 2). The second type represents the particles having an aerodynamic size between 400 and $500 \mathrm{~nm}$ and containing a $\mathrm{TiO}_{2}$ (cluster 3 ). The third type (Fig. 10c) (cluster 4) represents the carbonaceous particles having a size between 400 and $500 \mathrm{~nm}$. The increase and decrease of the percentage of particles containing sulfate is illustrated by the peak and trough (points $G$ ) depicted in Fig. 10b. The points $G^{\prime}$ depicted in Fig. 10a correspond to a decrease of hit rate according to the peak of sulfate and an increase of hit rate caused by the decrease of the percentage of sulfate. The point A in Fig. 10b shows the highest percentage of sulfate in parallel to a low hit rate shown in Fig. 10a. The point $S$ which corresponds to a maximum concentration of $\mathrm{TiO}_{2}$ (Fig. 10b) shows a very low value of scattering efficiency and hit rate (Fig. 10a). Regarding the points $P, R$ and 


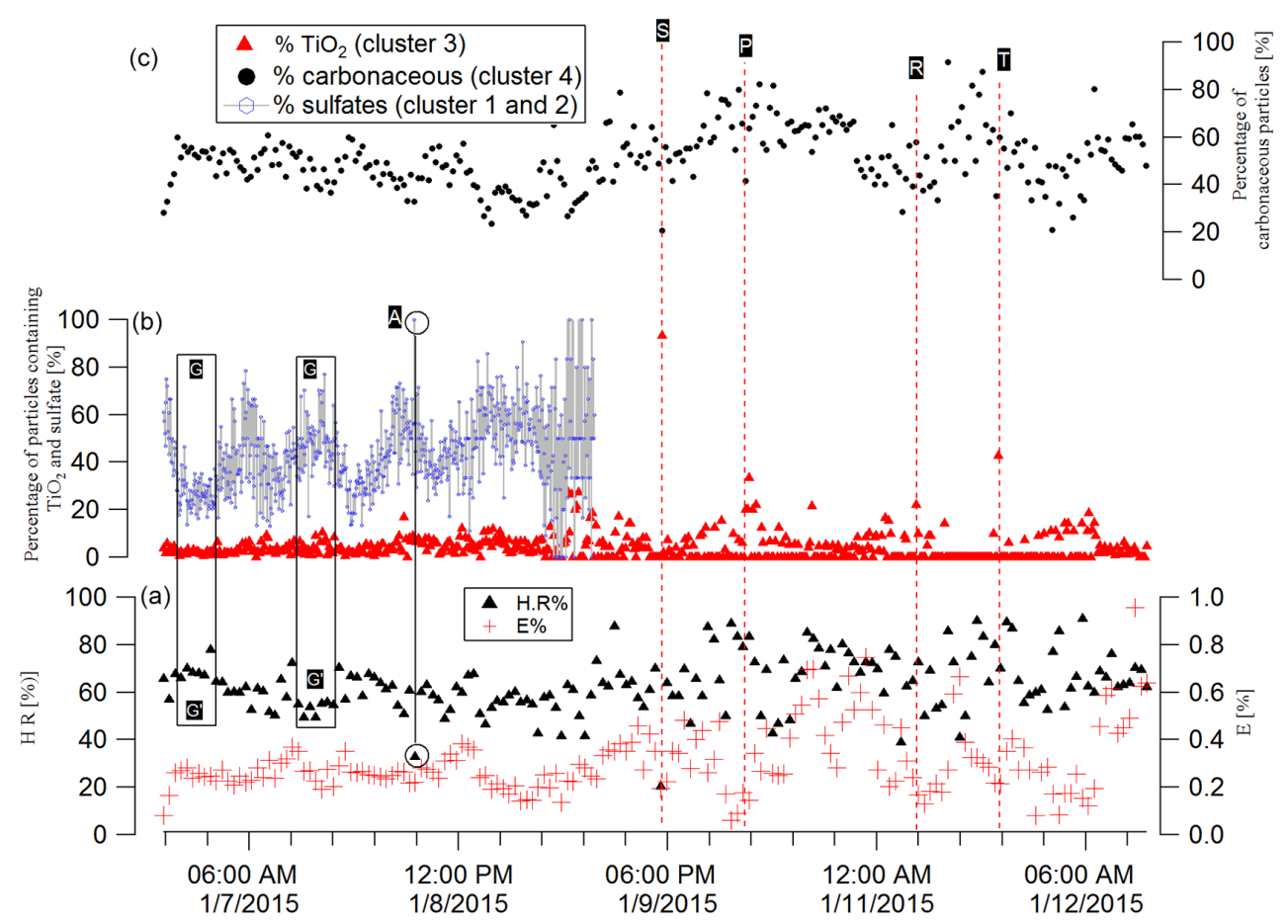

Figure 10. (a) The scattering laser $E(\%)$ and the evolution of the hit rate HR (\%) of the LAAP-ToF-MS for particles having a size between 400 and $500 \mathrm{~nm}$. (b) The evolution of the sulphate particles and the particles containing $\mathrm{TiO}_{2}$. (c) The evolution of the elemental carbon particles. $A, G$ and $G^{\prime}$ represent the influence of the percentage of sulphate containing particles on the HR (\%). $S$ corresponds to the maximum concentration of $\mathrm{TiO}_{2}$ and very low values of scattering efficiency and hit rate. $P, R$ and $T$ represent the influence of the percentage of carbonaceous particles on the scattering efficiency.

$T$ the number of carbonaceous particles decreases while the number of $\mathrm{TiO}_{2}$ particles increases. For these three points the scattering efficiency decreases, as well. The evolution of the carbonaceous particles before and after $S$ exhibits a similar behavior as the hit rate. Despite the effect that other particles could induce on these parameters, the comparison made in Fig. 10 emphasizes the importance of chemical composition toward the hit rate and the scattering efficiency.

Therefore, a simple separation by size range and a correction of the detection efficiency according to the size can no longer lead to the real concentration number because of the variation of the chemical composition. Thus, the average of the detection efficiency calculated for each size range is no longer adequate for a time interval of few minutes. Therefore, it is necessary to have a particle counter (like an OPC) to calculate the detection efficiency $\left(D_{n, t}\right)$ for each size range for every time interval. On the other hand, the total amount of particles must be separated in different classes $\left(C_{i}\right)$ based on their chemical composition. These classes must be separated in different size ranges $\left(C_{i, n}\right)$. Every $C_{i, n}$, according to its distribution during the time, must be multiplied by its corresponding $D_{n, t}$. The description of this method is out of scope of this article and therefore will be detailed and validated by comparison to another instrument elsewhere.

\section{Size calibration}

Ambient measurements showed that a significant amount of particles could be related to particles with a diameter less than $350 \mathrm{~nm}$, which is not the case for experiments with the spherical PSL particles during the calibration of the instrument. This can be explained by the fact that particles in ambient air have different optical characteristics, enabling them to scatter the light more efficiently at the scattering wavelength used in this instrument $(\lambda=405 \mathrm{~nm})$. Therefore, in order to precisely determine the diameter of the particles we carried out measurements related to the size calibration of the particles.

When a particle drifts through the particle-time-of-flight (P-ToF) chamber, it crosses the beam of two light scattering lasers. Upon passing the first laser beam, the scattered light from the particle is detected by the first photomultiplier tube (PMT). As explained above in the description of LAAPToF-MS, the flight time of an individual particle between the first and second scattering lasers is used to determine its velocity and associated vacuum-aerodynamic diameter. For the given beam separation distance of $11.5 \mathrm{~cm}$ between the two scatterings lasers the particle velocity was determined and plotted against the aerodynamic particle diameter (Fig. 11). 

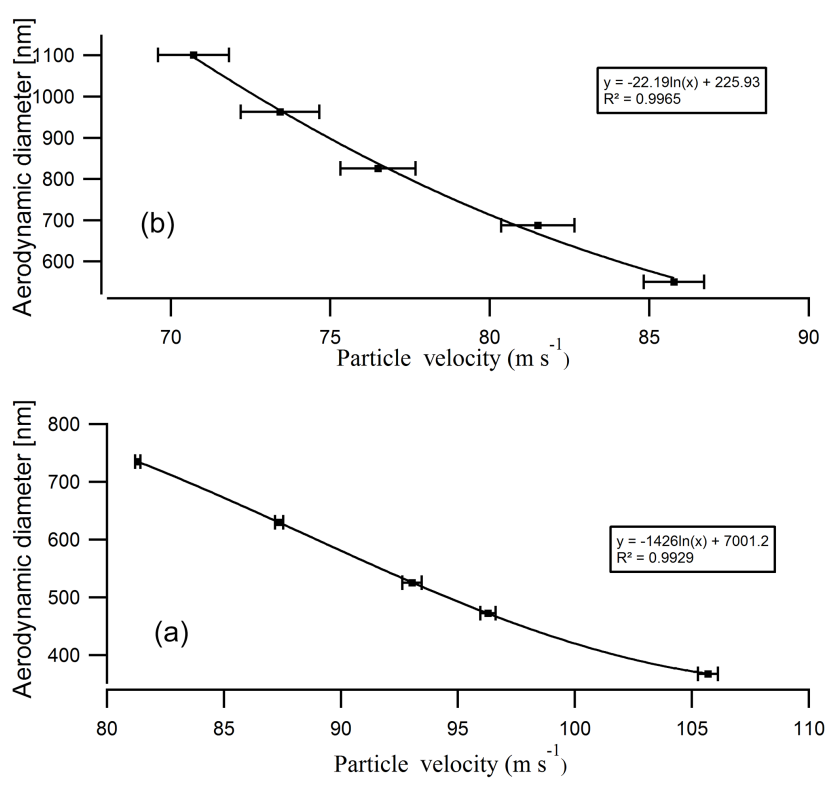

Figure 11. Plot of aerodynamic particle size versus particle velocity for (a) PSL particles and (b) ammonium nitrate particles.

Figure 11 shows the calibration curve for aerodynamic particle sizing measurements carried out for five certified sizes of PSL particles (a) and five different sizes of ammonium nitrate particles (b).

The experimental data were fitted with a first order exponential decay curve. The smallest PSL particles that can be precisely size-calibrated have a diameter of $350 \mathrm{~nm}$. However, the fitting equation depicted in Fig. 11 can serve to roughly estimate the size of atmospheric particles with an aerodynamic diameter smaller than $350 \mathrm{~nm}$.

\subsubsection{Particle number concentration effect}

\section{Laboratory experiments}

Prior to study the effect of number concentration, an upper limit of the particle number concentration $\left(C_{\max }\right)$ has been determined for each size to ensure that below this limit only a single particle is present in the space between the two scattering lasers. The obtained results presented in Fig. 12 indicate that $C_{\max }$ is linear and inversely proportional to the particle size.

For a particle size of $350 \mathrm{~nm}$, which is the smallest particle size that has been tested, $C_{\max }$ is $\approx 618$ particles $\mathrm{cm}^{-3}$. For higher particle number concentrations, more particles are present in the space between the two scattering lasers which indicates that smaller particulate matter with $d<200 \mathrm{~nm}$ can be detected but the obtained information corresponds to two different particles detected in very small frame of time. In other words, the spectrum obtained relates to a single, real particle, but the size information does not. Hence, the $E(\%)$ should decrease because the data of one single particle is

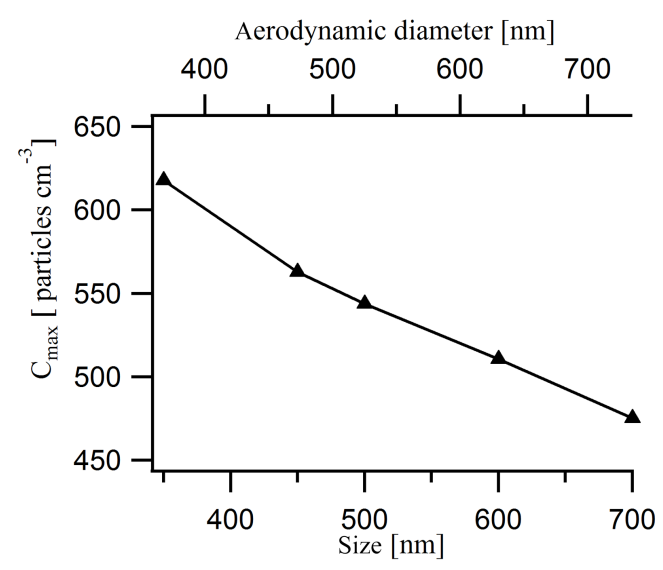

Figure 12. Variation of $C_{\max }$ for particles with different aerodynamic diameters.

recorded instead of two. In order to study the effect of a concentration higher than $C_{\max }$ on the $E(\%)$, ferric sulfate particles $(450 \mathrm{~nm})$ were generated at 5 different concentrations between 50 and 1200 particles $\mathrm{cm}^{-3}$. The higher level 1200 was chosen according to the value of $C_{\max }$ found at 562 particles $\mathrm{cm}^{-3}$ for particles with diameter of $450 \mathrm{~nm}$. The influence of particle concentration on the detection efficiency was assessed by comparison of the obtained RSD values based on at least three independent measurements.

Concerning the scattering efficiency $E(\%)$, it was expected that it decreases, but the RSD between the different concentrations is lower than the RSD between the repetitions for the same concentration, so the $E(\%)$ is considered constant. To study the effect of concentration number higher than $C_{\max }$ on the detection of particles lower than $200 \mathrm{~nm}$ to which the scattering lasers are blind, the percentage of these particles for the different concentration numbers studied was assessed (Fig. 13). Once the concentration is higher than the $C_{\max }, 562$ particles $\mathrm{cm}^{-3}$, the percentage of the particles with size lower than $200 \mathrm{~nm}$ increases from $1 \%$ for a concentration number of 40 particles $\mathrm{cm}^{-3}$ to $19 \%$ for a concentration number of 612 particles $\mathrm{cm}^{-3}$. This means that the detected particle with diameter lower than $200 \mathrm{~nm}$ corresponds to the detection of two different particles by the two scattering lasers.

\section{Ambient measurements}

The detected particles in the range between 250 and $350 \mathrm{~nm}$ (aerodynamic diameter) could be the result of two phenomena. The first one is the presence of a total concentration number higher than the $C_{\max }$ for all the particle sizes and the second one is the increase of the refraction index of the particles. A comparison of the results obtained by the OPC and the LAAP-ToF-MS, that has been undertaken for the particles ranging between 250 and $350 \mathrm{~nm}$ shows the reason why these particles were detected. The comparison of the re- 


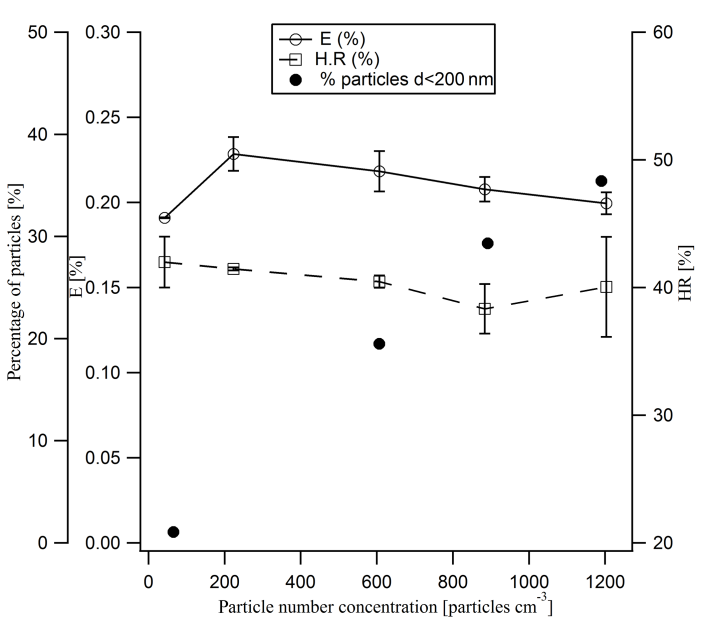

Figure 13. The hit rate and the scattering efficiency of $450 \mathrm{~nm}$ ferric sulfate particles as a function of the particle number concentration and the percentage of the particles having a size lower than $200 \mathrm{~nm}$ for different concentrations of generated particles.

sults is depicted in Fig. 14a where a similar evolution of the number of particles is shown for the two types of measurements. The figure indicates that the particles between 250 and $350 \mathrm{~nm}$ detected by the LAAP-ToF-MS are not a consequence of the total concentration of particles which was higher than the $C_{\max }$ during the 6 days of measurements.

Considering that the scattering laser is blind with respect to the particles with $d_{\mathrm{va}}<200 \mathrm{~nm}$ and that the aerodynamic lenses cannot transmit particles with $d_{\mathrm{va}}<80 \mathrm{~nm}$, the effect of $C_{\max }$ was evaluated as shown in Fig. 14b. Particles having an aerodynamic diameter between 0 and 80 and 0 and $200 \mathrm{~nm}$ were detected mainly when the number concentration of particles increased (Fig. 14b).

\section{Conclusions}

A recently developed LAAP-ToF-MS instrument has been calibrated and characterized.

In this work the performance of LAAP-TOF-MS has been characterized on standard spherical particles under controlled laboratory conditions and on ambient particles.

Prolonged on-line measurements revealed that the detection efficiency of LAAP-ToF-MS and the hit rate exhibits good repeatability with RSD of 17 and $18 \%$, respectively.

A comparison between the detection efficiency of LAAPToF-MS and the scattering efficiency of single particle laser ablation mass spectrometer (SPLAM) showed that the detection efficiency as a function of particle size is very similar.

A maximum detection efficiency of $2.5 \%$ was observed for particles with a diameter of $450 \mathrm{~nm}$ with a decreasing efficiency towards smaller sized particles. Therefore, to further increase the accuracy of the data it is essential to improve the detection efficiency for smaller particle sizes.

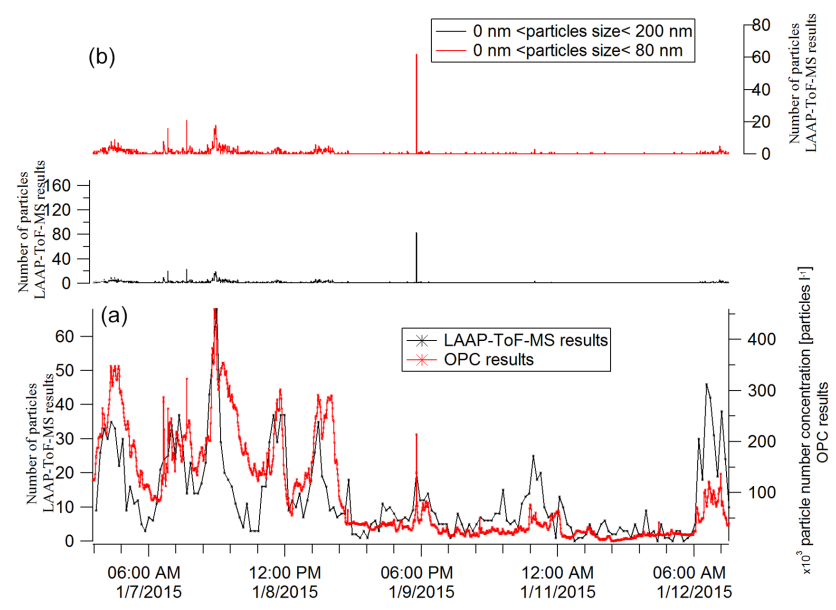

Figure 14. (a) The number of particles sizes between $200-300 \mathrm{~nm}$ detected by the LAAP-ToF-MS every $50 \mathrm{~min}$ and the number concentration detected every $5 \mathrm{~min}$ by the OPC for the particles sizes $250-300 \mathrm{~nm}$. (b) the number of particles having a size between 0 200 and $0-80 \mathrm{~nm}$ detected by the LAAP-ToF-MS every $5 \mathrm{~min}$.

Many parameters such as particle number concentration in the sample flow, the size of the particles, and the chemical composition, could change during a field campaign and affect the detection efficiency of the LAAP-ToF-MS. For this reason, the changing in the performances of this instrument caused by the parameters cited above was studied using laboratory and atmospheric particles. The temporal evolution of the particles was validated during the ambient aerosol measurements performed at the campus of Aix-Marseille University, situated in the city center of Marseille, France. The obtained results are in good agreement with the data obtained by optical particle counter and the $\mathrm{PM}_{2.5}$ data obtained by the local air monitoring station. Also several metal ions were detected during this field campaign such as lead, cerium, titanium and tin.

Therefore, LAAP-ToF-MS is a suitable instrument for online monitoring of atmospheric particles that can provide information on size distribution, number concentration and chemical composition of the detected particles.

Acknowledgements. This work is a contribution to the LABEX SERENADE (no. ANR-11-LABX-0064) funded by the "Investissements d'Avenir", French Government program of the French National Research Agency (ANR) through the A*Midex project (No. ANR-11-IDEX-0001-02).

The authors gratefully acknowledge the support of this work by French National Agency of Research within the ANR-10-EQPX39-01.

Edited by: P. Herckes 


\section{References}

Allen, J. O., Fergenson, D. P., Gard, E. E., Hughes, L. S., Morrical, B. D., Kleeman, M. J., Gross, D. S., Gälli, M. E., Prather, K. A., and Cass, G. R.: Particle Detection Efficiencies of Aerosol Time of Flight Mass Spectrometers under Ambient Sampling Conditions, Environ. Sci. Technol., 34, 211-217, 2000.

Buzea, C., Pascheco, I. I., and Robbie, K. Nanomaterials and Nanoparticles: Sources and Toxicity, Biointerphases, 2, 17-172, 2007.

Canagaratna, M. R., Jayne, J. T., Jimenez, J. L., Allan, J. D., Alfarra, M. R., Qi Zhang, Q., Onasch, B., Drewnick, F., Coe, H., Middlebrook, A. M., Delia, A., Williams, L. R., Trimborn, A. M., Northway, M. J., DeCarlo, P. F., Kolb, C. E., Davidovits, P., and Worsnop, D. R.: Chemical and Microphysical Characterization of Ambient Aerosols with the Aerodyne Aerosol Mass Spectrometer, Mass Spectrom. Rev., 26, 185-222, 2007.

Delmas, R., Mégie, G., and Peuch, V. H.: physique et chimie de l'atmosphère, edited by: Belin, Paris, France, 2005.

Dockery, D. W. and Pope, C. A.: Health Effects of Fine Particulate Air Pollution: Lines That Connect, J. Air. Waste. Manage., 56, 709-742, 2006.

Finlayson-Pitts, B. and Pitts, J.: Atmospheric Chemistry, Fundamentals and Experimental Techniques, Academic press, CA, USA, 2000.

Gaie-Levrel, F., Perrier, S., Perraudin, E., Stoll, C., Grand, N., and Schwell, M.: Development and characterization of a single particle laser ablation mass spectrometer (SPLAM) for organic aerosol studies, Atmos. Meas. Tech., 5, 225-241, doi:10.5194/amt-5-225-2012, 2012.

Gard, E., Mayer, J. E., Morrical, B. D., Dienes, T., Fergenson, D. P., and Prather, A. K.: Real-Time Analysis of Individual Atmospheric Aerosol Particles: Design and Performance of a Portable ATOFMS, Anal. Chem., 69, 4083-4091, 1997.

Lelieveld, J., Evans, J. S., Fnais, M., Giannadaki, D. and Pozze, A.: The Contribution of Outdoor Air Pollution Sources to Premature Mortality on a Global Scale, Nature International Weekly Journal of Science, 525, 367-371, 2015.
Liu, P., Ziemann, P. J., Kittelson, D. B., and McMurry, P. H.: Generating Particle Beams of Controlled Dimensions and Divergence: II. Experimental Evaluation of Particle Motion in Aerodynamic Lenses and Nozzle Expansions, Aerosol Sci. Tech., 22, 314-324, 1995.

Kane, D. B. and Johnston, M. V.: Enhancing the Detection of Sulfate Particles for Laser Ablation Aerosol Mass Spectrometry, Anal Chem., 73, 5365-5369, 2001.

Moffet, R. C. and Prather, A. K.: Extending ATOFMS Measurements To Include Refractive Index and Density, Anal. Chem. 77, 6535-6541, 2005.

Murphy, D.: The Design of Single Particle Laser Mass Spectrometers, Mass Spectrom. Rev., 26, 150-165, 2007.

Poeschl, U.: Atmospheric Aerosols: Composition, Transformation, Climate and Health Effects, Angew. Chem. Int. Edit., 44, 7520 7540, 2005.

Pratt, K. and Prather, K.: Mass Spectrometry of Atmospheric Aerosols-Recent Developments and Applications. Part II: OnLine Mass Spectrometry Techniques, Mass Spectrom. Rev., 31, 17-48, 2011.

Su, Y., Sipin, M., Furutani, H., and Prather, K.: Development and Characterization of an Aerosol Time-of-Flight Mass Spectrometer with Increased Detection Efficiency, Anal. Chem., 76, 712 719, 2004.

Yoo, S., Chae, S., and Liu, B.: Influence of Particle Refractive Index on the Lower Detection Limit of Light Scattering Aerosol Counters, Aerosol Sci. Technol., 25, 1-10, 1996.

Zauscher, M. D., Moore, M. J. K., Lewis, G. S., Hering, S. V., and Prather, K. A.: Size Range Critical for Cloud Formation, Anal. Chem., 2271-2278, 83, 2011.

Zelenyuk, A. and Imre, D.: Single Particle Laser Ablation Time-ofFlight Mass Spectrometer: An Introduction to SPLAT, Aerosol Sci. Technol., 39, 554-568, 2005. 